\title{
Business Process Driven Matching of Partner Profiles to Resource Requirements
}

\author{
Maik Herfurth ${ }^{1}$, Thomas Schuster ${ }^{1}$, and Peter Weiß ${ }^{2}$ \\ ${ }^{1}$ FZI Forschungszentrum Informatik, Haid-und-Neu-Str. 10-14, \\ 76131 Karlsruhe, Germany \\ \{herfurth, schuster\}@fzi.de \\ ${ }^{2}$ ISS International School of Service Management, Hans-Henny-Jahnn-Weg 9, \\ 22085 Hamburg, Germany \\ weiss@iss-hamburg.de
}

\begin{abstract}
Based on recent research in business process modeling and management enhanced integration of resource management can be beneficial. In this context appropriate resources can be identified by matching their profiles with business process requirements. Requirements may be generated from business process models as competence profiles, if advanced modeling techniques that enable detailed modeling are being used. Matching generated profiles to profiles of internal resources (typically maintained by human resource departments) or external business partners (organizations as well as individuals) requires profile descriptions at a similar level of detail. In order to enable sound matching of resource profiles between supplicants and suppliers in collaborative networks, we suggest modeling and system architecture that can handle these challenges. As one main pillar we will present a framework that allows formal description of competence profiles as well as their aggregation to common job profiles; we will outline this approach for the sector of information and communication technology (ICT). Formal description is accomplished by building profiles with the Resource Modeling Language (RML). Regarding architecture we focus on exchange and processing of profile description models. The practical application of our approach is demonstrated by formalization of competence descriptions given by the European eCompetence Framework (eCF).
\end{abstract}

Keywords: Collaborative Resource Management, Business Process Management, Resource Allocation, Resource Profile Aggregation.

\section{Introduction}

In many economic sectors the accumulation of company consortia in order to manage projects is fostered by emerging worldwide markets and broader access to foreign products, services, companies, and workforces. With the advent of enhanced communication technologies, the competition of companies in these global markets is increased. As a suitable response to these circumstances, companies need to adjust and improve their business processes continuously [3,9]. Throughout this competition 
partners and staff in formed collaborative business networks change fluently, which raises the need for finding and selecting new and appropriate partners. The increased interconnectedness of the markets furthermore strengthens the comparability of offers. As a result, business partner selection is one success key that companies need to manage [12]. Appropriateness of new partners can be measured in several dimensions such as reliability, performance, or quality of service.

Recent research investigated several metrics of the dimensions mentioned before for competence profiles $[6,10]$. In this context three research questions need to be addressed: (1) Which requirements have to be fulfilled by the new partners? (2) Which partners are capable to meet these requirements? (3) And how can these partners be found and contracted? An efficient identification of the requirements has to be based on the underlying business processes, available resources, and demanded competences. Thus competence based requirements (in this context often also referred to as profiles) can be identified and the difference to available resources can be calculated. In order to identify partners that meet these requirements a sound method to match offers with derived demands is needed. Apart from the calculation methods and models a similar level of abstraction and concept description in the models of bidders and buyers is needed to ease comparability. Finally, a platform that fosters a global view on market offers is needed. Today a multitude of platforms does exist, however, several different description methods are used and none of the existent platforms does offer a meta search concept.

\section{Modeling Resource Profiles}

Modeling of resource profile is related to two disciplines: business process management and human resource management. Common research approaches often foster the differentiation of business process and competence-based resource management. As a result both disciplines have utilized different modeling techniques with a minimal overlap. While this strict differentiation is also common in modeling and management techniques, several research studies [16,10,12] state that both disciplines are affected by each other. The additional strengths of an enhanced alignment of business process modeling and resource management (as mainly driven by human resource departments) have been outlined in [12]. The identification of appropriate resource requirements, such as needed competences, can be driven by an analysis of business processes managed by organizations. In this context the increased interdependence and continuous changes in business processes have to be considered.

\subsection{Modeling Requirements}

Resource-based analysis is subject of related research in collaborative networks [14]. Since resource requirements can only be identified in business processes if tasks contain quantitative and qualitative requirements; these requirements enclose properties of resources which may be assigned to tasks [10,11]. Yet the vast majority of business process driven resource classification schemes is based upon two dimensions only: role models and organizational hierarchies. Since the formulation and derivation of resource requirements tend to be tremendously complex, these two 
dimensions are insufficient to cover requirements of modern resource management (especially regarding scheduling mechanisms). Thus multidimensional, formal and machine readable approaches to business process modeling and resource description are required.

Resource description is primarily addressed by (human) resource management, hence a variety of standards describe possible attributes of (human) resources. These standards, however, either do not cover important properties necessary to describe resource requirements in business processes or are not well formalized and structured. One approach that covers the description of human resource competences is the European e-Competence Framework (e-CF), which is a result of an initiative at European level that succeeds several earlier approaches [5,4,15,1,2]. The framework currently describes 36 categories of competences for jobs in the information and communications technology sector. Nevertheless precise and formal definitions are not included. Other approaches to describe data related to human resource planning and competences such as HR-XML [7] and RCD [8] are XML-based languages.

Their data definitions are given by a set of XML schemas, thus these languages have an improved structural architecture. However these descriptions are restricted to certain aspects. Most organizational characteristics and different types of resources (non-human) are not reflected. Also on the subject of competence descriptions a distinction between the concepts skill, knowledge and competence is missing. In order to overcome these drawbacks of current approaches RML (Resource Modeling Language) as fine grained resource description approach fosters formalization [10]. RML is a precise and extensible language conforming to existing standards of competence descriptions.

\subsection{Sound Modeling of Resource Profiles}

The resource modeling language (RML) is a modeling approach that fulfills the described design requirements [10]. RML is based on a MOF-compliant meta model called resource meta-model (RMM). RMM is a multi-part meta model consisting of a specialized human resource meta-model (HRMM) and a competence meta-model (COMM). Existing standards such as RCD and HR-XML [8,7] have influenced the conceptual model of RMM, thus a transformation of existing descriptions in these standards can be transformed to RML. A detailed description of RML is beyond the scope of this paper, see [10] instead.

RML allows describing resources and reusable competence descriptions, similar to RCD or HR-XML. However RML enables modeling of details not covered by these standards, especially distinction of competences, skills and knowledge, as well as description of relationships and dependencies between concepts. This can be seen as particular advantage of RML. RML also enables linking of competence related information not only to personnel resources but also to role descriptions. Furthermore RML allows modeling of various organizational aspects (such as projects, groups, hierarchies or privileges). Figure 1 shows an example of a formal competence description represented in RML. The illustrated competence is called Solution Deployment 2 (compare to competence B.4 in [5]), directed connection means implies, therefore the competence shown in Figure 1 implies a set of skills, skills again imply several knowledge objects. 


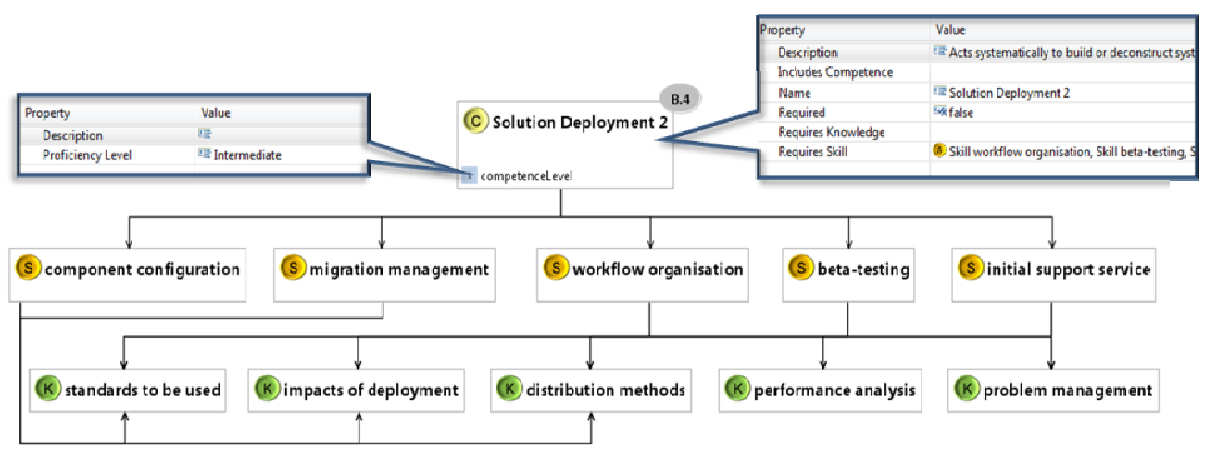

Fig. 1. RML Instance Solution deployment

Many details of RML model elements cannot be part of the graphical model, they are modeled as properties instead (see annotations left and right of the competence element shown in Figure 1). According to its MOF-compliant meta model, the RML editor stores this information in an XML-Format (which is XMIcompliant). An organizational description exemplified as RML model is depicted in Figure 2. In following example, properties of human resources (here Joe Smith) are outlined. In shown example model Joe Smith is working for an organizational unit (ITDepartment) in an organizational group (SOATeam). He possesses one role (EntrepriseDeveloper) and works currently in a project (AgileCoupling). For simplicity not all details of the illustrated model elements are covered, instead properties of Joe Smith (shown in the box left to the element) are set.

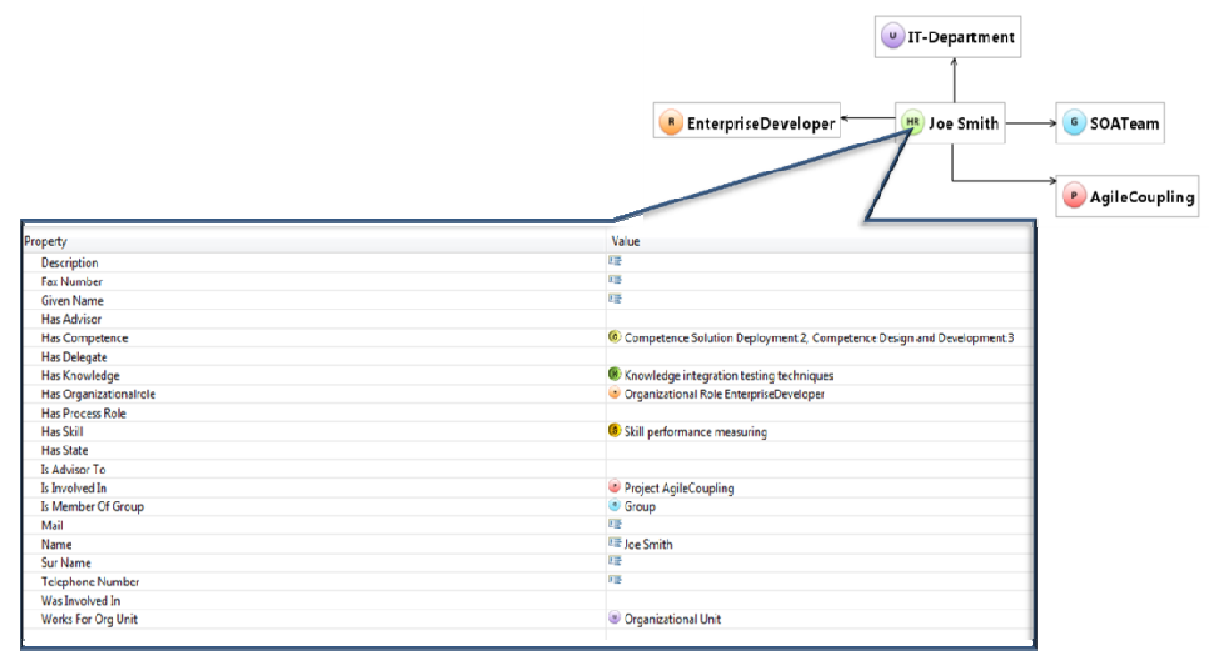

Fig. 2. Linking competence description to organizational resources 
Competence related concepts are looked at particularly. According to introduced RML meta model human resources can possess set of competences, skills and knowledge besides those determined by the roles assigned. Described relationships are defined as properties shown in the box left of referred model element "Joe Smith". Thus, besides requirements of assigned organizational role (EnterpriseDeveloper) Joe Smith possesses in addition competence "Solution Deployment 2" (which we outlined in Figure 1).

\section{Job Profiles in ICT}

Under the umbrella of CEN/ISSS Workshop on ICT Skills, an expert group is currently working on a project named "Towards e-Job Profiles" which elaborates job profiles based on the European e-Competence Framework (e-CF) [13,19]. Standardized ICT job profiles are seen to facilitate required level of interoperability imposed in the context of collaborative networks. Standardized descriptors and common modeling languages are needed and considered to be an enabler. Job profiles help building position descriptions and career paths within an organization or collaborative network. Various views and applications can be identified in connection with job profiles.

According to [24] two concepts lay the foundations to describe job profile descriptions, namely required competences and desired results/deliverables. The latter refers to the competence definition of [17]: "Competence is demonstrated ability to apply knowledge, skills and attitudes for achieving observable results". Attitudes equate with cognitive and relational capacity. Learning outcomes referring to knowledge and skills are seen as link to qualification systems (European Qualification Framework (EQF)). Job profiles are classified into groups using criteria as customer contact (relational capacities), technical skills and domains (cognitive capacities), and required proficiency or associated hierarchy level (e.g. associate, technician, expert, principal, etc.). Thus job profiles are mostly composed of the following elements: title and short definition, tasks overview, behavior, deliverables, competences, required resources, performance indicators, dependencies and interfaces. List of ICT profiles can be found in [20,21,22]. Applications are spanning from provision of students with information concerning possible career paths to assistance of HR managers in analyzing and planning competence requirements or development of ICT curricula for training and qualification measures. Standardized ICT job profiles support bidirectional and flexible communication with business partners forming company's ecosystem. Make-or-buy decisions can be better planned and based on company's strategy and business processes.

Business processes or activities can be outsourced or contracted in short or longer term. This necessitates transparency of requirements and competences needed to run types or classes of business processes. The European e-Competence Framework differentiates four dimensions which deliver descriptors reflecting levels of business and resource planning requirements. Dimension 1 addresses competence areas referring to typical ICT business process phases within an ICT organization, namely plan, build, run (or operate), enable and manage [13]. Job profiles are supported through an online tool developed within the e-CF project. However, the e-CF does not 
offer or use a formal model or representation language allowing transformation of competence descriptions. Competence-based professional profiles aim defining and exchanging information about respective professional or performance standards. Profiles describe set of competences required to operate business processes, render and deliver services or refer to a specific position or role as part of a working team or project. Competence based profiles are built without any particular reference to an individual or employee [22,23]. Job profile description given as natural language description can be formalized by means of RML [10]. In conjunction with standardized profile descriptions the use of RML can result in sound calculations to determine appropriate business partners as well as new employees.

Table 1. ICT Profiles of AITTS [22]

\begin{tabular}{|l|l|}
\hline Group & Profiles \\
\hline Administrator & Administrator \\
\hline Customer Advisor & $\begin{array}{l}\text { IT Sales Advisor } \\
\text { IT Service Advisor } \\
\text { IT Trainer }\end{array}$ \\
\hline Coordinator & $\begin{array}{l}\text { IT Project Coordinator } \\
\text { IT Quality Management Coordinator } \\
\text { IT Security Coordinator }\end{array}$ \\
\hline $\begin{array}{l}\text { Software and Solution } \\
\text { Developer }\end{array}$ & $\begin{array}{l}\text { Digital Media Developer } \\
\text { IT Tester } \\
\text { Software Developer }\end{array}$ \\
\hline Technician & $\begin{array}{l}\text { Component Developer } \\
\text { Industrial IT Systems Technician } \\
\text { Security Technician }\end{array}$ \\
\hline
\end{tabular}

\section{Information Exchange in Collaborative Scenarios}

In collaborative networks (compare Fig. 3) a multitude of stakeholders is involved in the execution of inter-organizational business processes. Thus in order to ensure appropriate communication standardized message formats and service interfaces may be used. In order to identify appropriate business partners, profiles and requirements need to be described in a similar way: by the same description language and on a similar level of abstraction. Thus implementation of collaborative networks requires availability of standards to support business interactions. [19, p. 151] describe capabilities of companies to maintain partnerships and sustain strategic ecosystems supporting business transformations and "servicization" as driving force of "value chain redesign".

Business partner relationship management requires organizational structures with abilities to self-manage, self-configure and self-optimize besides the necessary culture "[...] semantic-informed self-organizing structures [...]" [23, p.8]. Semantics of profile data has to be made explicit or based on shared standards. Thus a set of competences is proposed as extension in form of a view or additional section of the 
concept of Business Partner Profiles (BPP) introduced by [24]. Formal representation of competence descriptions as suggested in section 2 would allow applying techniques such as information retrieval to collect information from network partners.

In our opinion continuous analysis of company's business processes reveals competence gaps and supports strategic decisions and planning concerning make-orbuy-decisions. In figure 3 for instance a collaborative business process can be automatically supported by a broker - process requirements can be met by suggested suppliers (see process step competence requirements), if requirements and profiles are provided adequately. Thus business processes analysis and modeling should in future take into account competence requirements. Furthermore information of competence requirements has to be exchanged amongst business partners forming the value chain. This necessitates a common language or formal representation allowing exchange of information or data stored in respective HR-systems. Typically, systems do fulfill required interoperability because data models do not match [17]. Secondly means of a service oriented platform can address data exchange itself, however a bunch of issues (e.g. security and confidentiality) has to be solved by such a platform.

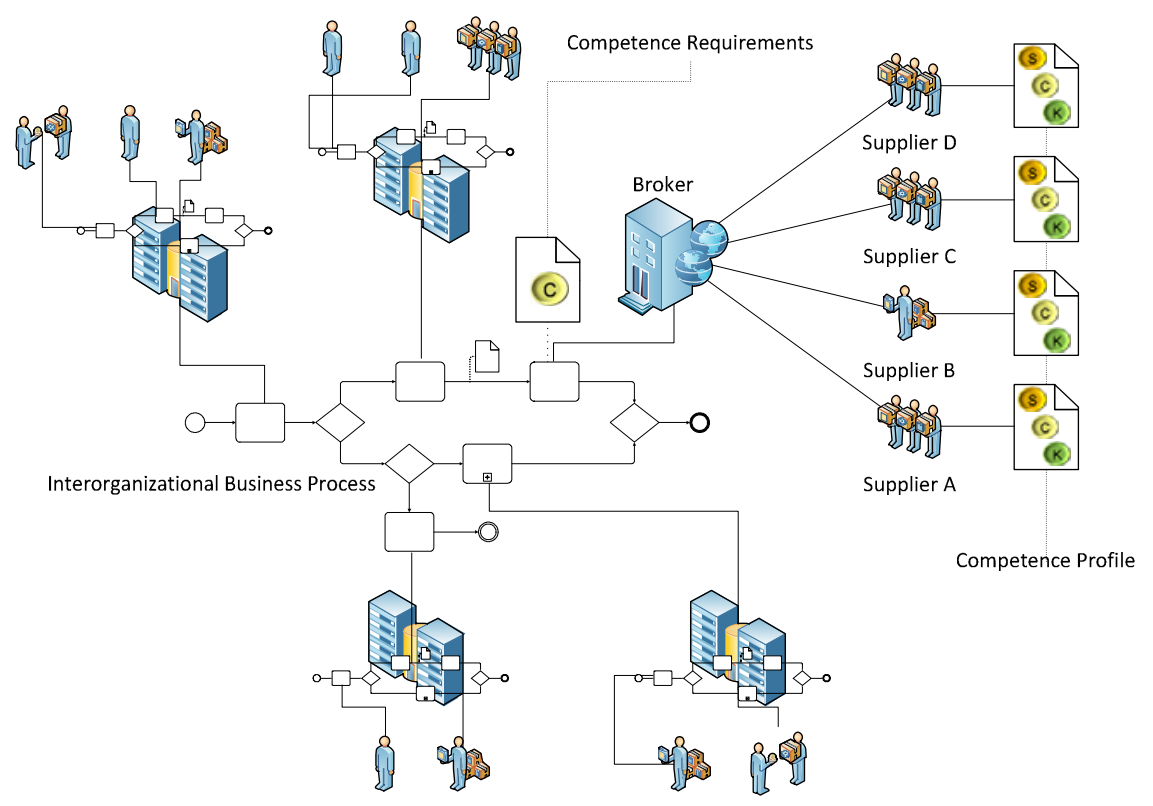

Fig. 3. Collaborative Network Scenario

\section{Conclusion}

In collaborative networks data exchange between participating actors and the challenge to match available information of resource profiles comes to the fore. Standards to ensure exchange of competence requirements and definitions between 
organizations are needed. On basis of the presented modeling language and method interoperable resource profiles can be described and analyzed. The presented resource modeling language (RML) demonstrates the potential of the combination and extension of known concepts in resource modeling, competence modeling and business process management. Competence and resource models of human resource departments can be re-used for the modeling of business process relevant requirements to resources. Furthermore existing competence models can be adapted to the actual business process requirements. In network scenarios organizations can create and exchange comparable resource models by employing the out method of goal oriented modeling guidelines.

Therefore models can be used to improve sound recruitment of new partners. To extend concepts outlined in this paper, we plan to develop mechanisms for competence gap analysis and automatic aggregation of competence profiles. Finally we strive to generate resource models automatically from existing data by the usage of transformation rules in regard to the goal oriented modeling guidelines. In order to validate the given theoretical approach and future calculation methods the evaluation in a service oriented broking scenario will be desirable.

\section{References}

1. CEN Workshop Agreement. CWA 14925: Generic ict skills profiles for the ICT supply industry-a review by CEN/ISSS ICT-skills workshop of the career space work (2004)

2. CEN Workshop Agreement. CWA 15893-1: European e-competence framework (2008)

3. Doubrovski, V., Grundler, J., Hogg, K., Zimmermann, O.: Service-oriented architecture and business process choreography in an order management scenario: Rationale, concepts, lessons learned. In: OOPSLA 2005, San Diego (2005)

4. eCCO. A european e-skills meta-framework. Technical report, AICA, Federcomin, Fondazione Politecnico di Milano. Draft Proposal (2005)

5. European e-Competence Framework 2.0. A common European framework for ICT Professionals in all industry sectors. Technical report, CEN (2010)

6. Hlaoittinun, O., Bonjour, E., Dulmet, M.: Managing the competencies of team members in design projects through multi-period task assignment. In: Camarinha-Matos, L., Boucher, X., Afsarmanesh, H. (eds.) Collaborative Networks for a Sustainable World. IFIP AICT, vol. 336, pp. 338-345. Springer, Boston (2010)

7. HR-XML Consortium, Competencies (2007/2009)

8. IEEE Learning Technology Standards Committee. RCD: Draft standard for reusable competency definitions (RCD) (2006)

9. Lenz, K., Oberweis, A.: Interorganizational business process management with xml nets. In: Ehrig, H., Reisig, W., Rozenberg, G. (eds.) Petri Net Technology for CommunicationBased Systems. LNCS, vol. 2472. Springer, Heidelberg (2003)

10. Oberweis, A., Schuster, T.: A meta-model based approach to the description of resources and skills. In: Proceedings of 16th Americas Conference on Information Systems, AMCIS 2010 (2010)

11. Russell, N., van der Aalst, W.M.P., ter Hofstede, A.H.M., Edmond, D.: Workflow Resource Patterns: Identification, Representation and Tool Support. In: Pastor, Ó., Falcão e Cunha, J. (eds.) CAiSE 2005. LNCS, vol. 3520, pp. 216-232. Springer, Heidelberg (2005) 
12. Schuster, T., Weiß, P.: A new approach to competence-based business partner profiles for collaborative business process management. In: Camarinha-Matos, L., Boucher, X., Afsarmanesh, H. (eds.) Collaborative Networks for a Sustainable World. IFIP AICT, vol. 336, pp. 356-363. Springer, Heidelberg (2010)

13. The European e-Competence Framework. CEN workshop agreement (CWA 15893 (part 1 \& 2)). Technical report, CEN (2008)

14. van der Aalst, W.M.P., Kumar, A.: Xml-based schema definition for support of interorganizational workflow. Information Systems Research 14(1), 23-46 (2003)

15. Winterton, J., Delamare-Le Deist, F., Stringfellow, E.: Typology of knowledge, skills and competences: clarification of the concept and prototype. In: Cedefop 2005 (2005)

16. zur Mühlen, M.: Organizational management in workflow applications-issues and perspectives. Information Technology and Management 5, 271-291 (2004); Appendix: Springer-Author Discount

17. Povalej, R., Stucky, W., Weiß, P.: Conceptual Data Model for Data Interchange between HR Information Systems. In: The 11th International Conference on Informatics and Semiotics in Organisations, IFIP WG8.1 Working Conference (ICISO 2009): Information Systems in the Changing Era: Theory and Practice, IFIP WG8.1 Working Conference Proceedings. IFIP WG8.1, IEEE Press and submitted for index by INSPEC, EI (Compendex) and ISTP, April 11-12, Oral Session 11: Information Systems (4) (2009)

18. Weiß, P., Klink, S.: Collaborative services to maintain electronic business relationships. In: Camarinha-Matos, L., et al. (eds.) PRO-VE, Band Establishing The Foundation of Collaborative Networks, IFIP TC 5 Working Group 5.5 Eighth IFIP Working Conference on Virtual Enterprises, Guimarães, Portugal, Seiten 435442, Boston, September 10-12. IFIP. Springer, Heidelberg (2007)

19. CEN/ISSS Workshop on ICT Skills: Towards e-Job profiles based on the European eCompetences Framework,

http: / / www. cen.eu/CEN/sectors/sectors/isss/activity/Pages / wsict-skills.aspx (last visited April 14, 2011)

20. ICT Careers Portal, Australian Computer Society, http: / / www.acs.org.au/ictcareers / (last visited April 14, 2011)

21. EUCIP Elective Profiles,

http://www.ecdl.org/files/eucip/docs / 20080527022608 Intro_\&2 0EUCIP 20Professional\%20v2 . 4 .pdf (last visited April 14, 2011)

22. AITTS (Advanced IT Training System), 14 specialist profiles, http://www.cert-it.com/en/it-specialists/the-14-profiles/ (last visited April 14, 2011)

23. Camarinha-Matos, L.M., Afsarmanesh, H.: Processes and Foundations for Virtual Organizations. In: IFIP TC5/WG5.5, Proceedings PRO-VE 2003 (2003)

24. Weiß, P., Klink, S.: Collaborative Services to Maintain Electronic Business Relationships. In: Proceedings of Eighth IFIP Working Conference on Virtual Enterprises, September 1012. Springer, Boston (2007) 